\title{
Outcomes of Our Laparoscopic Surgery in Colorectal Cancer: Our First Experiences
}

\section{Kolorektal Kanserde Laparoskopik Cerrahi Sonuçlarımız: İlk Deneyimlerimiz}

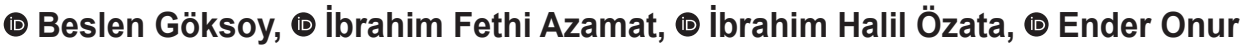 \\ Şehit Prof. Dr. İlhan Varank Training and Research Hospital, Clinic of General Surgery, İstanbul, Turkey
}

\section{|IIIIIII| ABSTRACT}

Aim: The laparoscopic approach in colorectal surgery is widely applied in experienced centers. In this study, we aimed to present the short-term results of our first laparoscopic experience on the patients with primary diagnosis of colorectal cancer (CRC) in our newly opened hospital.

Method: Between 10 August 2018-1 November 2019, patients who underwent elective laparoscopic surgery with the primary diagnosis of CRC in the Sancaktepe Şehit Prof. Dr. İlhan Varank Training and Research Hospital, Clinic of General Surgery were included in the study. Demographic characteristics, type of surgery, duration of surgery, pathology results, length of hospitalization, first bowel movements time, oral intake starting days, drainage catheter removal time, rate of conversion to open surgery, complications and early mortality were evaluated.

Results: A total of 20 patients (11 male, 9 female) were included in the study. The median age was 60 (41-80) years. The most performed operation was the right hemicolectomy (50\%). In 3 (15\%) patients laparoscopic surgery was converted to open surgery. Three (15\%) patients developed wound infection, hematoma was seen in $1(5 \%)$ patient, and 1 patient $(5 \%)$ developed ileus. The mean operative time was $172 \pm 31$ min and the duration of hospitalization was 7 days (5-15). The total number of dissected lymph nodes was higher in female patients $(\mathrm{p}=0.02)$. There was a positive correlation between operation time and length of hospitalization $(\mathrm{p}=0.016, \mathrm{r}=0.532)$, and tumor diameter and oral intake time $(\mathrm{p}=0.03$, $\mathrm{r}=0.621)$. There was no anastomotic leakage or early mortality.

Conclusion: Especially our rate of conversion to open surgery, complications, and oncologic outcomes were in line with the literature.

Keywords: Laparoscopic colorectal surgery, colorectal cancer, experience

\section{|IIIIIII| ÖZ}

Amaç: Kolorektal cerrahide laparoskopik yaklaşım deneyimli merkezlerde yaygın olarak uygulanmaktadır. Bu çalışmada, yeni açılan hastanemizde primer kolorektal kanser (KRK) tanısı alan hastalardaki ilk laparoskopik deneyimlerimizin kısa dönem sonuçlarını sunmayı amaçladık.

Yöntem: Sancaktepe Şehit Prof. Dr. İlhan Varank Eğitim ve Araştırma Hastanesi Genel Cerrahi Kliniği'nde, 10 Ağustos 2018-1 Kasım 2019 tarihleri arasında KRK tanısı ile laparoskopik ameliyat olan hastalar çalışmaya dahil edildi. Hastaların demografik özellikleri, ameliyatın tipi, ameliyat süresi, patoloji sonuçları, hastanede kalış süresi, ilk gaz-gayta çıkış zamanı, oral gıda başlama günleri, dren çekilme zamanı, açığa dönüş oranı, komplikasyonlar ve erken dönem mortalite değerlendirildi.

Bulgular: Toplam 20 hasta (11 erkek, 9 kadın) çalışmaya dahil edildi. Yaş ortalamaları 60 (41-80) idi. En fazla sağ hemikolektomi (\%50) uygulandı. Üç hastada (\%15) açığa dönüldü, 3 hastada (\%15) yara yeri enfeksiyonu, 1 hastada (\%5) yara yeri hematomu, 1 hastada (\%5) ileus gelişti. Ortalama ameliyat süresi $172 \pm 31 \mathrm{dk}$ ve hastanede yatış süresi 7 gündü (5-15). Toplam diseke edilen lenf nodu sayısı kadın hastalarda daha fazla saptandı $(\mathrm{p}=0,02)$. Ameliyat süresi ile hastanede yatış süresi arasında $(\mathrm{p}=0,016, \mathrm{r}=0,532)$ ve tümör çapı ile oral gıda başlama zamanı arasında pozitif bir korelasyon olduğu saptandı ( $\mathrm{p}=0,03, \mathrm{r}=0,621$ ). Anastomoz kaçağı ve erken dönem mortalite görülmedi.

Sonuç: Başta açığa dönüş oranımız olmak üzere komplikasyonlarımız ve onkolojik sonuçlarımız literatürle benzer bulunmuştur.

Anahtar Kelimeler: Laparoskopik kolorektal cerrahi, kolorektal kanser, deneyim

Address for Correspondence/Yazışma Adresi: Beslen Göksoy, MD,

Şehit Prof. Dr. İlhan Varank Training and Research Hospital, Clinic of General Surgery, İstanbul, Turkey

E-mail: beslengoksoy@gmail.com ORCID ID: orcid.org/0000-0001-6006-9438

Received/Gelis Tarihi: 09.01.2020 Accepted/Kabul Tarihi: 21.03.2020

${ }^{\circ}$ Copyright 2020 by Turkish Society of Colon and Rectal Surgery

Turkish Journal of Colorectal Disease published by Galenos Publishing House. 


\section{Introduction}

Colorectal cancer (CRC) is considered one of the leading causes of morbidity and cancer-related deaths nationally and worldwide. According to GLOBACAN 2018 data, approximately $10 \%$ of cancers are CRC. Approximately $1,800,000$ new CRC cases are detected each year, and approximately 850,000 are estimated to result in death. ${ }^{1}$

In the early 1990s, laparoscopic colorectal surgery applications started. There are many significant advantages compared to open surgery, such as less hospitalization time, less perioperative blood loss, earlier postoperative recovery of the patient, better cosmetic results, less analgesic requirement, and faster return of the gastrointestinal system functions. ${ }^{2}$ More importantly, it has no negative impact on oncological results. In a randomized controlled study published by the Japan Clinical Oncology Group in 2019, a total of 1,057 patients (laparoscopic 529, open 528) who underwent surgery for stage $2 / 3$ colon cancer were evaluated, and no difference was found between 2 groups in terms of recurrence and overall survival. ${ }^{3}$

The laparoscopy learning curve is high in colorectal surgery, especially rectum cancer, which has a limited work area due to the narrow pelvis. In the international multicenter systematic analysis performed by Miskovic et al. ${ }^{4}$, a total of 4,852 cases were evaluated in 7 studies, and it was shown that the learning curve was an average of 152 cases for translation, an average of 143 cases for complications, and 96 cases for operation time.

Although CRC mortality mainly depends on the disease stage, there has recently been a growing interest in the effects of hospital-related factors on outcomes after CRC resection. ${ }^{5}$ In a study using the National Inpatient Sample (NIS) data in 2019, complication and mortality rates were lower in highvolume and urban hospitals in patients operated for CRC. ${ }^{6}$ In our study, the surgeries were performed by surgeons who had laparoscopic surgery experience $(n>500$ laparoscopic cholecystectomy), participated in more than 50 surgeries as the first assistant with experienced surgeons, but were less experienced in laparoscopic colorectal surgery $(\mathrm{n}=10$ 15). They participated in laparoscopic colorectal surgery training courses organized by the Turkish Society of Colon and Rectal Surgery. In this study, we aimed to present the first cases with CRC in whom we performed laparoscopic surgery in our newly established hospital. Our primary goal is to determine our conversion rate from laparoscopic to open surgery and secondarily compare the duration of surgery, pathology results, duration of hospitalization, perioperative complications, and early mortality rates with the literature.

\section{Materials and Methods}

\section{Patients}

Patients who had laparoscopic surgery due to CRC in the General Surgery Clinic of Sancaktepe Şehit Prof. Dr. Ilhan Varank Training and Research Hospital between 10 August 2018-1 November 2019 were included in the study. Patient files were scanned retrospectively for the data. Demographic features, diagnoses, tumor localization, type of surgery, duration of surgery, tumor diameter, total number of lymph nodes and metastatic lymph nodes dissected, stages, hospital stay, first postoperative bowel movement time, watery and normal food starting days to the patient, drainage catheter removal time, conversion from laparoscopic to open surgery, complications and early mortality were examined. Patients with laparoscopic surgery for palliative purposes were excluded from the study. The duration of hospital stay was defined as the period beginning with the patient's hospitalization and lasting until the day before the patient was discharged. The operation time was defined as the time from the first skin incision to the last skin suture. The conversion to open surgery was defined as laparoscopic incomplete dissection or laparotomy incision of $10 \mathrm{~cm}$ or above. All patients were evaluated at the oncology council at the outer center with preoperative and postoperative pathology results. All patients underwent colonoscopy in our clinic, and after the pathology was reported as malignant, intravenous (iv) contrast-enhanced (Optiray ${ }^{\circledR}$ 350) abdominal and thorax tomographies were performed for preoperative staging purposes. Also, iv contrast-enhanced (Magnevist ${ }^{\circledR}$ ) pelvic MRI was performed in rectum tumors. Information about the operation was verbally explained to all patients, and written consent was obtained. Preoperative American Society of Anesthesiologists (ASA) scores were recorded. Liquid food and mechanical bowel cleansings (2 Phospho-Soda ${ }^{\circledR} 21.6 \mathrm{~g}+8.1 \mathrm{~g} / 45 \mathrm{Ml}$ and 2 Fleet Enema ${ }^{\circledR}$ $133 \mathrm{~mL}$ ) were started the day before surgery. Low molecular weight heparin (LMWH) (Oksapar 4000 anti-Xa IU/0.4 $\mathrm{mL}$ subcutaneous injection) was performed for deep vein thrombosis (DVT) prophylaxis 8-10 hours before surgery.

Preparation for blood transfusion was done, antibiotic prophylaxis ( $2 \mathrm{~g}$ cefazolin iv) was performed half an hour before surgery, and patients wore medium pressure anti embolic socks on the morning of surgery. Possible stoma locations of patients with left colon and rectum tumors were marked before surgery. Antibiotic dose was repeated in patients whose operation time exceeded 4 hours. All patients were operated on by the same surgical team (G.B. and A.I.). It was planned to converse from laparoscopic to open surgery if oncological reliability was uncertain or surgical margins were suspicious. DVT prophylaxis was 
performed in all patients during their stay beginning from the day of surgery, and DVT prophylaxis continued after discharge for one month. The patients were invited to the outpatient clinic control on the 10th day after discharge and when the pathology results were obtained (on average 3-4 weeks). Early complications that occurred in patients were recorded. The 8th edition of the American Joint Committee on Cancer (AJCC) was used for staging.

All the procedures applied to the subjects are under the Helsinki Declaration of 1964, and the healing principles published afterward, and the institutional ethics committee approval was not received because of the retrospective study. Written informed voluntary consent form was taken from all patients included in the study.

\section{Operation Technique}

Pneumoperitoneum was performed by applying 12-14 mmHg pressure using a Veress needle with carbon dioxide gas. A thirty-degree vision camera was used, and a 10 mm trocar (Ethicon ${ }^{\circledR}$ or Covidien ${ }^{\circledR}$ ) was placed from the infra umbilical region for the camera port (in the right colon surgeries, the trocar was placed through the umbilicus junction on the midclavicular line). The ports, their numbers, and entry points varied depending on the procedure to be performed (Figure 1). In the first two right colonic tumors, the specimen was retrieved from the $5-\mathrm{cm}$ incision above the umbilicus, and the anastomosis was made with linear staples extracorporeally. The staples opening was closed in double layers with 3/0 vicryl. In all other surgeries, the specimen was removed from the 5-6 cm Pfannenstiel

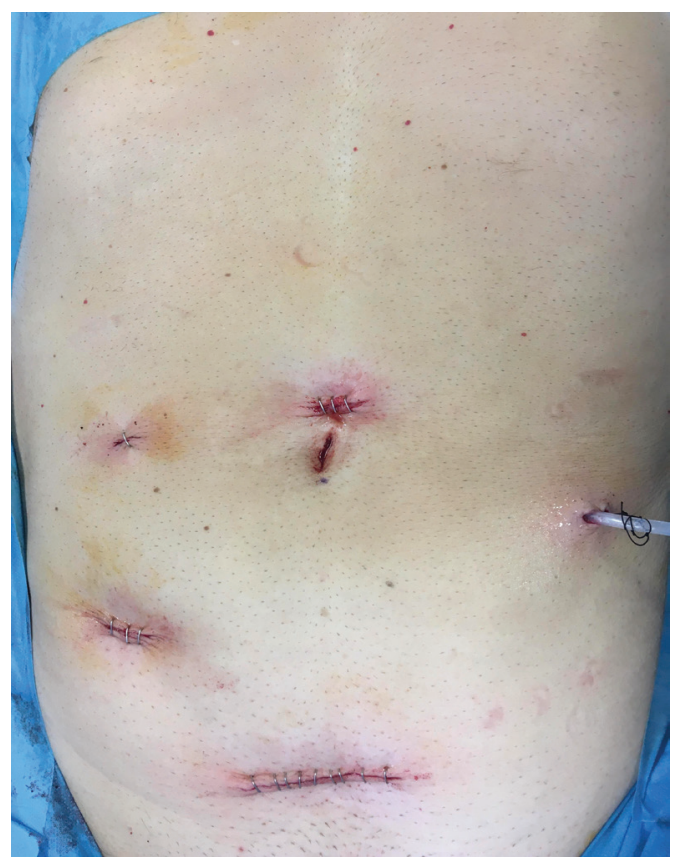

Figure 1. Post-operative image of a patient undergoing surgery due to a tumor located in the rectum incision. Wound dressing (Alexis ${ }^{\circledR}$ Wound Protector/ Retractor) was used in all patients to retrieve the specimen. Laparoscopic procedures were routinely performed by proximal ligation of the blood vessels (inferior mesenteric artery for the left colon and rectum, ileocolic artery for the right colon) and medial to lateral dissection, and a total mesocolic or total mesorectal excision technique was applied. Fully mobilization of splenic flexure was performed for left colon and rectal resection. In tumors located in the right colon, side-by-side ileo-transverse anastomosis was performed intracorporeally with a laparoscopic stapler (Ethicon ${ }^{\circledR}$ or Covidien ${ }^{\circledR}$ ), and the stapler opening was closed laparoscopically with a single layer of primary suture (The V-LocTM or $2 / 0$ vicryl). For tumors in the left colon and rectum, the anvil was placed extracorporeally at the end of the colon graft, and the pneumoperitoneum was obtained, the 31-mm circular stapler (Covidien ${ }^{\circledR} 31 \mathrm{~mm}$ $4.8 \mathrm{~mm}$ ) placed in the distal colon by the anal route and an end-to-end anastomosis was performed. The stapler rings were controlled. In rectum tumor surgeries, diverting loop ileostomy was used in the lower right quadrant. A silicone drainage catheter (Jackson-Pratt ${ }^{\circledR} 10 \mathrm{~mm}$ ) was routinely placed in the abdomen in all patients.

\section{Statistical Analysis}

The Shapiro-Wilk test was used to test for the normality of data. Normally distributed Numerical variables with normal distribution were shown as mean \pm standard deviation (SD), ordinal data and numerical variables with extreme values or without normal distribution were shown as median (minimum-maximum). Pearson correlation analysis was used for data with normal distribution, and Spearman correlation analysis was used for ordinal data or data without normal distribution. Statistical analyzes were performed using SPSS package software (Version: 21.0) for Windows ${ }^{\circledR}$. The data obtained were evaluated at a 95\% confidence interval and a 5\% significance level.

\section{Results}

Laparoscopic surgery was performed in 22 patients for CRC; two patients were operated for palliative purposes and were excluded from the study. A total of 20 patients were included in the study. Eleven (55\%) were male, 9 (45\%) were female, and the median age was 60 (41-80). Body mass index (BMI) average was $26 \pm 3 \mathrm{~kg} / \mathrm{m}^{2}$ (Table 1 ). Right hemicolectomy was the most common procedure $(n=10,50 \%)$ in this study. Two patients underwent simultaneous cholecystectomy for symptomatic cholecystolithiasis.

Preoperatively undetected small intestine invasions were detected at a distance of $20 \mathrm{~cm}$ and $110 \mathrm{~cm}$ from the Treitz ligament in one patient operated for a sigmoid colon 
tumor. Laparoscopic anterior resection and en-block partial intestinal resection were performed, the specimen was removed from the incision above the umbilicus. Intestinal anastomosis was provided by linear staplers, and colorectal anastomosis was performed as previously described by obtaining pneumoperitoneum again. In the pathologic evaluation, invasion was detected in both small intestine segments removed as en-block, and the surgical margins were reported as negative (T4bN0). Regarding the T stage, pT3 was detected in 17 patients (85\%), pT2 in 2 patients (10\%), and pT4B in 1 patient (5\%). In the pathologic examination of a patient who underwent extended right hemicolectomy due to a tumor located in the hepatic flexure, a second tumor focus (pT1) was detected $5 \mathrm{~cm}$ proximal to the primary tumor (pT3).

The average number of lymph nodes dissected was $29 \pm 12$, and the total number of lymph nodes dissected in female patients was significantly higher than in male patients $(\mathrm{p}=0.02)$. Pathology results are shown in Table 2. Three patients had superficial wound infection at the Pfannenstiel incision line, and an empirical oral antibiotic (Augmentin-BID 1,000 mg PO) was initiated after a sample was taken for culture. There was no growth in the culture, and the patient was treated with dressing. In a patient using oral anticoagulants due to chronic atrial fibrillation (Coumadin $5 \mathrm{mg}$ PO), a hematoma developed under the Pfannenstiel incision, and the hematoma was drained on the 5 th postoperative day. A patient with a rectum tumor with a history of gastric

İTable 1. Clinical features of patients

\begin{tabular}{ll} 
& $\begin{array}{l}\text { Mean } \pm \text { SD } \\
\text { Median (minimum- } \\
\text { maximum) }\end{array}$ \\
\hline Age (year) & $60 \pm 11$ \\
BMI $\left(\mathrm{kg} / \mathrm{m}^{2}\right)$ & $26 \pm 3$ \\
Gender, $\mathrm{n}(\%)$ & $11(55)$ \\
Male & $9(45)$ \\
Female & 7 \\
ASA score, $\mathrm{n}$ & 11 \\
I & 2 \\
II & \\
III & $10(50)$ \\
Tumor localization, $\mathrm{n},(\%)$ & $8(40)$ \\
Right colon & $2(10)$ \\
Left colon & \\
Rectum &
\end{tabular}

SD: Standard deviation ulcer who received neoadjuvant treatment [chemotherapy + radiotherapy (CRT)] had recurrent vomiting after surgery. A diagnostic laparoscopy showed that the small bowel was stuck to the anterior abdominal wall at $20 \mathrm{~cm}$ proximal to the diverting loop ileostomy. Complaints of the patient healed after laparoscopic bridectomy, and the patient was discharged.

The laparoscopic procedure was converted to open surgery in 3 patients (15\%) (Table 3). The first patient was operated on because of a tumor located in the hepatic flexure. In the patient with suspected duodenum invasion, there was suspicion of the surgical margin, oncologically. The operation was terminated without a duodenal resection requiring a negative surgical margin due to seeing that the tumor adhered to the duodenum by desmoplastic reaction. The second patient with conversion was operated on due to the tumor located in the sigmoid colon. After the dissection during colon resection, a firing problem in laparoscopic stapler and laparoscopic procedure was converted to open surgery. Both these patients were reported as pT3NO, and no recurrence was detected in their follow-up after one year. The third patient was a distal rectum tumor who received neoadjuvant CRT. Laparoscopic resection can not be done because of the narrow pelvis. Anastomosis was completed laparoscopically by resecting with Pfannenstiel incision through a stapler (Covidien TA Auto Suture, $60 \mathrm{~mm}-4.8$ $\mathrm{mm}$ ). The drainage catheter was removed between 4-6 days after the first postoperative bowel movements depending on the incoming content and the patient's clinic (regardless of the amount received). A positive correlation was found between the duration of surgery and hospital stay $(\mathrm{p}=0.016$, $\mathrm{r}=0.532$ ) and between tumor diameter and onset time of oral

Table 2. Pathology results

$\begin{array}{ll} & \begin{array}{l}\text { Mean } \pm \text { SD } \\ \text { Median } \\ (\text { minimum-maximum })\end{array} \\ \text { Tumor diameter }(\mathrm{cm})^{*}, \mathrm{n} & 5 \pm 2 \\ \text { Total number of lymph nodes, } \mathrm{n} & 29 \pm 12 \\ \text { Number of metastatic lymph nodes, } & 0(0-7) \\ \text { n } & \\ \text { TNM Staging (pathologic), } \mathrm{n} & \\ 1 & 2 \\ \text { 2A } & 8 \\ \text { 2C } & 1 \\ \text { 3B } & 7 \\ \text { 3C } & 2\end{array}$

*The tumor diameter was based on the largest size of the tumor (e.g. if tumor size was $6.5 \times 3 \mathrm{~cm}$, the tumor diameter was defined as $6.5 \mathrm{~cm}$ ) 
Table 3. Peroperative characteristics and postoperative complications

Type of surgery, n, (\%)

Right hemicolectomy $10(50)$

Anterior resection

Low anterior resection

Left hemicolectomy

$3(15)$

\section{Complications}

Wound site infection

Wound site hematoma

Ileus

Anastomosis leakage

Conversion to open surgery

Mortality (postoperative 30 days)

Hospitalization (day)

Duration of surgery (minute)

First bowel movements and ileostomy working time (day)

Flatus

Feces

İleostomy

Time to start oral food (day)

Watery food

Normal food

food intake ( $p=0.03, r=0.621)$. None of our patients had an anastomosis leak, and we had no early mortality.

\section{Discussion}

In our study, laparoscopic procedure was converted to open surgery in 3 (15\%) patients. It was found that significantly more lymph nodes were harvested in female patients. It was found that there was a relationship between the prolongation of the operation time and the duration of hospital stay, and it was observed that the time to start oral intake was prolonged as the tumor size increased.

The conversion to open surgery depends on many factors. In a study on conversion rates in laparoscopic colorectal surgery, a total of 1,253 patients were evaluated. The conversion rate was determined as $10 \%$, and BMI $(>28.5$ $\mathrm{kg} / \mathrm{m}^{2}$ ), ASA score (>3), resection type (left hemicolectomy and low anterior resection), surgeon's experience, and the presence of intraoperative abscess or fistula were found to be independent risk factors of conversion to open surgery. ${ }^{7}$ In another study conducted by Masoomi et al. ${ }^{8}$, a total of
207.311 patients were evaluated using the NIS database, and the conversion rate was determined as $16.6 \%$, and the conversion rate was highest in patients with proctectomy surgery. It was reported that the complication and mortality rates were higher in patients with conversion to open surgery. ${ }^{8}$ In our study, the only complication requiring reoperation occurred in a patient with conversion, as described.

In CRC surgery, it is recommended to remove a minimum of 12 lymph nodes in terms of correct staging and good prognosis. ${ }^{9}$ In particular, it has been reported in studies that the number of lymph nodes removed in stage 2 (T3N0) disease directly affects oncological results. ${ }^{10,11,12}$ The relationship between gender and the number of lymph nodes removed is not clear. Studies show no difference between the genders in terms of the number of lymph nodes removed. ${ }^{13,14}$ In contrast, in a study by Orsenigo et al. ${ }^{15}$ in 2019, 2,319 patients with colorectal surgery were evaluated, and the number of lymph nodes removed was higher in women $(p=0.02)$. A minimum of 14 lymph nodes (14-61) 
were harvested in our study, and significantly more lymph nodes were excised in female patients.

Bleeding, ureteral injury, adhesion, intestinal obstruction, and particularly anastomosis leakage are the most common complications, and reoperation may be required. In a systematic review made by Chang et al. ${ }^{16}$, a total of 11 studies were examined, and the most common complication requiring reoperation was anastomotic leakage. In patients who develop complications following initial laparoscopic colorectal resection, laparotomy will lose the benefits of laparoscopic surgery. Laparoscopic intervention in these patients may potentially preserve initial benefits. In our study, an early adhesion ileus developed in one patient. It was managed laparoscopically, and the patient was discharged without a problem. In T4 tumors, mostly if they are fixed or adjacent organ invasion, laparoscopic approach can be difficult, so $\mathrm{T} 4$ tumor is one reason that increases the rate of conversion to open surgery. ${ }^{17}$ In such locally advanced tumors, more extensive surgical procedures are required, including en-block resection of the infiltrated organ.

In the CLASSIC study, the main reason for conversion was found to be fixed tumors with a frequency of $41 \% .{ }^{18}$ In another study conducted by Bretagnol et al. ${ }^{19}$, the results of laparoscopic surgery in T4 tumors were evaluated, and the rate of conversion to open surgery was determined as $18 \%$. Also, it has been emphasized that the results of the laparoscopic approach in locally advanced tumors are similar to open surgery oncologically, and the laparoscopic approach should not constitute a contraindication in locally advanced tumors. ${ }^{19}$ In our study, simultaneous small bowel invasion was detected in a patient with sigmoid colon tumor, and en-block resection was done laparoscopically, as described. Publications are stating that the average operation time is 180 minutes (60-430 minutes) during the learning phase. ${ }^{20}$ In our study, we found our average operation time as $172 \pm 31$ minutes. We found that our operation time decreased after the first ten patients, although it was not statistically significant.

After abdominal and pelvic cancer surgery, DVT risk increases two-fold, and PE risk increases three-fold. ${ }^{21}$ In randomized controlled studies, prolonged prophylaxis (4 weeks) has been shown to reduce the risk of venous thromboembolism (VTE), and similarly, administration of LMWH for four weeks is recommended in the ACCP guideline. ${ }^{22,23,24,25}$ Prophylaxis was applied to our patients for one month, and no bleeding or VTE was detected clinically. In the study by Nijhof et al. ${ }^{26}$ performed in patients undergoing laparoscopic colorectal surgery in 2017; 523 patients were evaluated. Experienced surgeons and supervised trained surgeons were compared, and no difference was found between them in terms of patient safety and short-term results. ${ }^{26}$
Our surgery volume in about 15 months, we observed that $60 \%$ of the surgeries were performed in last 3-month period and our rate, which was one every 2-3 weeks, increased to once a week. We anticipate that our results will be better as our experience increases.

\section{Study Limitations}

The small number of patients and the study's retrospective design were the main limitations of the study. In contrast, complete patient follow-ups and data were the strengths of the study.

\section{Conclusion}

We determined that our conversion rate was the primary goal of our study, and our secondary results, such as complications and oncological results, were similar to the literature. We think that laparoscopic colorectal surgery can be performed in newly opened hospitals with sufficient equipment, provided to patient health and oncological principles.

\section{Ethics}

Ethics Committee Approval: The institutional ethics committee approval was not received because of the retrospective study.

Informed Consent: Informed voluntary consent form was taken from all patients included in the study.

Peer-review: Internally peer reviewed.

\section{Authorship Contributions}

Surgical and Medical Practices: B.G., İ.F.A., Concept: B.G., İ.H.Ö., E.O., Design: B.G., İ.H.Ö., E.O., Data Collection or Processing: B.G., İ.H.Ö., Analysis or Interpretation: B.G., E.O., Literature Search: B.G., İ.F.A., E.O., Writing: B.G., İ.F.A., E.O.

Conflict of Interest: No conflict of interest was declared by the authors.

Financial Disclosure: The authors declared that this study received no financial support.

\section{References}

1. Bray F, Ferlay J, Soerjomataram I, Siegel RL, Torre LA, Jemal A. Global cancer statistics 2018: GLOBOCAN estimates of incidence and mortality worldwide for 36 cancers in 185 countries. CA Cancer J Clin 2018;68:394424 .

2. Shanker B-A, Soliman M, Williamson P, Ferrara A. Laparoscopic Colorectal Training Gap in Colorectal and Surgical Residents. JSLS 2016;20:e2016.00024.

3. Fujii S, Akagi T, Inomata M, Katayama H, Mizusawa J, Ota M, Saito S, Kinugosa Y, Yamaguchi S, Sato T, Kitano S, Japan Clinical Oncology Group. Transitional impact of short- and long-term outcomes of a randomized controlled trial to evaluate laparoscopic versus open surgery for colorectal cancer from Japan Clinical Oncology Group Study JCOG0404. Ann Gastroenterol Surg 2019;3:301-309. 
4. Miskovic D, Ni M, Wyles SM, Tekkis P, Hanna GB. Learning Curve and Case Selection in Laparoscopic Colorectal Surgery: Systematic Review and International Multicenter Analysis of 4852 Cases. Dis Colon Rectum 2012;55:1300-1310.

5. Schrag D, Panageas KS, Riedel E, Hsieh L, Bach PB, Guillem JG, Begg CB. Surgeon volume compared to hospital volume as a predictor of outcome following primary colon cancer resection. J Surg Oncol 2003;83:68-78.

6. Hamidi M, Hanna K, Omesiete P, Cruz A, Ewongwo A, Pandit V, Joseph $\mathrm{B}$, Nfonsam $\mathrm{V}$. Does it matter where you get your surgery for colorectal cancer? Int J Colorectal Dis 2019;34:2121-2127.

7. Tekkis PP, Senagore AJ, Delaney CP. Conversion rates in laparoscopic colorectal surgery: a predictive model with, 1253 patients. Surg Endosc 2005; 19:47-54

8. Masoomi H, Moghadamyeghaneh Z, Mills S, Carmichael JC, Pigazzi A, Stamos MJ. Risk Factors for Conversion of Laparoscopic Colorectal Surgery to Open Surgery: Does Conversion Worsen Outcome? World J Surg 2015;39:1240-1247.

9. Fielding LP, Arsenault PA, Chapuis PH, Dent O, Gathright B, Hardcastle JD, Hermanek P, Jass JR, Newland RC. Clinicopathological staging for colorectal cancer: An International Documentation System (IDS) and an International Comprehensive Anatomical Terminology (ICAT). J Gastroenterol Hepatol 1991;6:325-344.

10. Le Voyer TE, Sigurdson ER, Hanlon AL, Mayer RJ, Macdonald JS, Catalano PJ, Haller DG. Colon Cancer Survival Is Associated With Increasing Number of Lymph Nodes Analyzed: A Secondary Survey of Intergroup Trial INT-0089. J Clin Oncol 2003;21:2912-2919.

11. Tepper JE, O'Connell MJ, Niedzwiecki D, Hollis D, Compton C, Benson $A B$, Cummings B, Gunderson L, Macdonald JS, Mayer RJ. Impact of Number of Nodes Retrieved on Outcome in Patients With Rectal Cancer. J Clin Oncol 2001;19:157-163.

12. Swanson RS, Compton CC, Stewart AK, Bland KI. The Prognosis of T3NO Colon Cancer Is Dependent on the Number of Lymph Nodes Examined. Ann Surg Oncol 2003;10:65-71.

13. Baxter NN, Virnig DJ, Rothenberger DA, Morris AM, Jessurun J, Virnig BA. Lymph Node Evaluation in Colorectal Cancer Patients: A Population-Based Study. J Nat Cancer Inst 2005;97:219-225.

14. Ong MLH, Schofield JB. Assessment of lymph node involvement in colorectal cancer. World J Gastrointest Surg 2016;8:179.

15. Orsenigo E, Gasparini G, Carlucci M. Clinicopathological Factors Influencing Lymph Node Yield in Colorectal Cancer: A Retrospective Study. Gastroenterol Res Pract 2019;2019:1-6.
16. Chang KH, Bourke MG, Kavanagh DO, Neary PC, O'Riordan JM. A systematic review of the role of re-laparoscopy in the management of complications following laparoscopic colorectal surgery. Surgeon 2016;14:287-293.

17. Veldkamp R, Kuhry E, Hop WCJ, Jeekel J, Kazemier G, Bonjer HJ Laparoscopic surgery versus open surgery for colon cancer: short-term outcomes of a randomised trial. Lancet Oncol 2005;6:477-484.

18. Jayne DG, Guillou PJ, Thorpe H, Quirke P, Copeland J, Smith AMH, Heath RM, Brown JM, UK MRC CLASICC Trial Group. Randomized Trial of Laparoscopic-Assisted Resection of Colorectal Carcinoma: 3-Year Results of the UK MRC CLASICC Trial Group. J Clin Oncol 2007;25:3061-3068.

19. Bretagnol F, Dedieu A, Zappa M, Guedj N, Ferron M, Panis Y. T4 colorectal cancer: is laparoscopic resection contraindicated?: Laparoscopic T4 colorectal cancer. Colorectal Dis 2011;13:138-143.

20. Tekkis PP, Senagore AJ, Delaney CP, Fazio VW. Evaluation of the Learning Curve in Laparoscopic Colorectal Surgery: Comparison of Right-Sided and Left-Sided Resections. Ann Surg 2005;242:83-91.

21. Geerts WH, Bergqvist D, Pineo GF, Heit JA, Samama CM, Lassen MR, Colwell CW. Prevention of Venous Thromboembolism. Chest 2008;133:381S-453S

22. Emoto S, Nozawa H, Kawai K, Hata K, Tanaka T, Shuno Y, Nishikawa T, Sasaki K, Kaneko M, Hiyoshi M, Murona K, Ishihara S. Venous thromboembolism in colorectal surgery: Incidence, risk factors, and prophylaxis. Asian J Surg 2019;42:863-873.

23. Gould MK, Garcia DA, Wren SM, Karanicolas PJ, Arcelus JI, Heit JA, Samama CM. Prevention of VTE in Nonorthopedic Surgical Patients. Chest 2012;141(2 Suppl):e227S-e277S.

24. Kakkar VV, Balibrea JL, Martínez-González J, Prandoni P, On Behalf Of The Canbesure Study Group. Extended prophylaxis with bemiparin for the prevention of venous thromboembolism after abdominal or pelvic surgery for cancer: the CANBESURE randomized study: Prolonged thromboprophylaxis in cancer surgery. J Thromb Haemost. 2010;8:12231229 .

25. Vedovati MC, Becattini C, Rondelli F, Boncompagni M, Camporese G, Balzarotti R, Mariani E, Flamini O, Pucciaeralli S, Donini A, Agnelli G. A Randomized Study on 1-Week Versus 4-Week Prophylaxis for Venous Thromboembolism After Laparoscopic Surgery for Colorectal Cancer: Ann Surg 2014;259:665-669.

26. Nijhof HW, Silvis R, Vuylsteke RCLM, Oosterling SJ, Rijna H, Stockmann HBAC. Training residents in laparoscopic colorectal surgery: is supervised surgery safe? Surg Endosc 2017;31:2602-2066. 